\title{
Workplace bullying and its effect on organizational trust and turnover Intention among nursing staff.
}

\author{
Alzahraa Abdel Aziz Omer ${ }^{1}$ \& Shereen Faiyez Gabra ${ }^{2}$ \\ 1. Lecturer of Psychiatric Nursing Department, Faculty of Nursing, Minia University, Egypt. \\ ${ }^{2 .}$ Lecturer of Nursing Administration Department, Faculty of Nursing, Minia University, Egypt.
}

\begin{abstract}
Background: Workplace bullying is a psychosocial and organizational problem within the health care system, which affect negatively in nurses' organizational trust and their turnover intention. Aim: Assess workplace bullying and its effect on organizational trust and turnover intention among nursing staff. Design: A descriptive correlational design was utilized to achieve the objective of the present study. Sample: A stratified random sample of 301 nurses were selected from Minia university hospitals. Setting: This study was conducted at Minia university hospitals, At Minia city. Egypt. Tools: four tools were utilized in this study: I: Socio-demographic Data, II: Workplace Bullying Questionnaire, III: organizational trust questionnaire and, IV: turnover intension questionnaire Results: Illustrates that about two third of staff nurses had the highest percentage level regarding workplace bullying, and less than two third of them had the lowest percentage level regarding the organizational trust and more than two third of them had the highest percentage level regarding turnover intension. Conclusion: The conclusions of the current study showed that, there were strong a positive correlation between workplace bullying and turnover intension. While there were a negative correlation between work place bullying and organizational trust, and a negative correlation between turnover intension and organizational trust for study subjects. Recommendations: health care organization should encourage supervisors to use effective communication skills and inspire perspicuous standards and guidelines to identify and battle workplace bullying to improve organizational trust and reduce turnover intention among nursing staff.
\end{abstract}

\section{Keywords: Organizational trust, Turnover intension \& Workplace Bullying.}

\section{Introduction}

Nursing is the foundation of the health-care system, which is continually faced with new obstacles, issues, and opportunities. Nurses are always at the forefront when there is a need for treatment, whether in hospitals, community health centers, or isolated nursing stations. To ensure quality and foster a culture of safety, health care facilities must resolve the issue of behaviors that compromise the health care team's efficiency. Workplace bullying (WPB) is a global social and organizational epidemic in the health-care sector that has a variety of negative implications for nurses' job satisfaction and efficiency. (Yamada et al., 2018). Workplace Bullying is described by the Workplace Bullying Institute (WBI) as "repeated, health-harming mistreatment of one or more individuals by one or more perpetrators." It is aggressive, degrading, or intimidating behaviors, or job interference that prevents work from being completed, or verbal violence (Alliance, 2016).

People exhibiting behaviors jointly with each other as part of the scope of universal moral rules can be described as confidence. Organizational trust is a distinct yet measurable mechanism involving the actions of individuals in an organizational system who share a sense of accuracy, confidence, engagement, and sincerity with one another. Interorganizational trust is crucial in a number of organizational activities and times, including cooperative behavior growth, performance assessment, goal management, leadership, team spirit formation, organizational engagement, and contribution to employee satisfaction (Fard \& Karimi, 2015).

The role of organizational confidence in the performance of organizations cannot be overstated. For most organizations 'trust is a crucial problem because it can bring major benefits. Organizational trust is a psychological condition that offers guidance on how workers view challenges in circumstances where the organization's survival is in jeopardy. High levels of confidence are expected to lead to high levels of business etiquette (work satisfaction, organizational commitment, and so on), positive organizational practices (such as organizational citizenship behavior), and high levels of performance (Top et al., 2015).

An employee's voluntary willingness to leave an organization is referred to as turnover intention (Yang et al., 2014). Nurse turnover is a global problem that, if not handled properly, can have a 
detrimental effect on an organization's productivity. The health system is severely harmed by the high turnover rate of health staff, particularly in countries with limited resources. As a result, successful retention strategies necessitate a thorough understanding of the factors at work that affect nurses' decisions to remain or leave their employer (Gebregziabher et al., 2020).

Several studies have shown that hospital-related factors (such as the hospital profitability index, working environment, and interpersonal relationships), as well as occupational or technical factors, can affect nurses' decisions to stay or leave their jobs (include role- dilemmas, patient-initiated violence, work hours, risky working condition), employee characteristics (such as age, educational readiness, and work attitude) (Hayes et al., 2012 \& Takase, 2010) Similarly, several researchers conclude that workplace bullying is related to the decision to leave (Bahjat et al.,2017; Coetzee \& Oosthuizen, 2017; Coetzee \& van, 2017).

The healthcare sector is notorious as a typical working environment with a high risk of WPB, which has a negative effect on both hospitals and individuals. For a hospital, this may result in higher absenteeism, which has a negative impact on productivity, quality, and profitability. Repeated exposure to negative actions at work may deplete coping resources, preventing individuals from coping with everyday work tasks; additionally, it may increase employee turnover, impacting the health care organization financially as inexperienced staff recruitment and retraining is a costly process; and finally, it may increase employee turnover, affecting the health care organization financially as novice staff recruitment and retraining is a costly process (Al Omar et al., 2019).

Workplace bullying may also have a number of negative effects for people, such as anxiety, tension, frustration, trauma marks, and a decrease in interpersonal functioning. It can also result in a lack of self-confidence and a sense of frustration with life. According to research, not only the victims of WPB, but also those who witnessed it, experienced elevated levels of anxiety (Nagib \& Mohamed, 2020).

The health-care team wants a work atmosphere that is marked by confidence and reverence, and in which they have the resources and expertise required to achieve the organization's goals and objectives. Interactions between health care team members are affected by confidence, which is a concept that is viewed as truthful and founded on reality. As a result, they are able to share their thoughts and emotions, use one another as tools, and learn from one another (Elewa \& El Banan, 2019 \& Ayangeawam et al., 2014). Similarly, Chen et al., (2015) Employees that have high levels of organizational confidence are more responsible and innovative, and organizational trust increases work satisfaction, organizational engagement, and productivity. It also encourages teamwork, centralization of problems, constructive communication, and knowledge sharing, and can compensate for employees' limited abilities.

\section{Significance of the Study :}

Nurses are vital members of the healthcare team, with primary roles including responding to evolving healthcare demands and achieving organizational priorities and goals. Nowadays, occupational bullying is a major issue that is on the rise in the healthcare sector, and it has gained increased attention domestically and globally over the past two decades, impacting nurse efficiency and rising turnover rates. Organizational confidence, on the other hand, is a crucial component of a healthy workplace and is recognized as one of the most important entraining factors for organizational success. Improved nurse faith in their company, as well as their ability to work there in the long run, should be a top priority for health care executives (Basit \& Duygulu, 2018).

Bullying in the workplace and the threat of retribution are extreme, unresolved problems that have an effect on employees and passers-by. As a consequence, according to the researchers, it is crucial to examine the definition in order to establish important strategies for maintaining, trusting, and using staff nurses. Therefore it was felt necessary to assess workplace bulling and its effect on organizational trust and turnover intention among nursing staff.

Aim of the study.

Assess workplace bullying and its effect on organizational trust and turnover intention among nursing staff.

\section{Research questions}

1. What is the level of workplace bullying, organizational trust and turnover intention among nursing staff?

2. Is there a relationship between workplace bullying, organizational trust and turnover intention among nursing staff?

\section{Subjects and Method \\ Research design}

A descriptive correlational research design was used for the current study.

Setting

This study was conducted at Minia university hospitals, including (Minia emergency university hospital - Gynecology, Obstetric and Pediatric University hospital - Urology university hospital Liver and digestive system hospital and cardiothoracic hospital) at Minia city, Egypt. 


\section{Sample Size}

It was estimated at confidence interval $95 \%$, margin of errors $5.0 \%$, a total population size of 1215 staff nurses, by using formula, provided by Yamane, (1967) $[\mathrm{n}=\mathrm{N} / 1+\mathrm{N}(\mathrm{e}) 2]$; the required sample size was (301) nurses. A stratified random sample was used.

\section{Data collection tool}

Data collected by using four tools as following.

Tool I: Socio-demographic Data: It used to collect data about nursing staff and encompass item such as age, sex, residence, marital status educational level, department, and years of experience.

Tool II: Workplace bullying measured by using Negative Acts Questionnaire-Revised (NAQ-R): -

The English form of this tool was developed by Einarsen et al., (2009) in English language to assess nurses' perception of workplace bullying. It consists of 22 items with five Likert scale ranged as $(1=$ never; $2=$ now and then; $3=$ monthly; $4=$ weekly; $5=$ daily). The instrument includes three dimensions workrelated bullying ( 7 items), person-related bullying (12 items), and physical intimidation (3 items). The tools' reliability was checked and statistically measured. Cronbach's Alpha test was used to determine the tools' internal accuracy which was (0.90). The scoring system was ranged from (22 to 110), and it divided into three levels as follow:

- Low workplace bullying from 22 to 51

- Moderate workplace bullying from 52 to 81

- High workplace bullying from 82 to 110 .

\section{Tool III: Organizational Trust Scale}

This tool developed by Dirks \& Ferrin, (2002) in English language to assess organizational trust. It consists of 27 items were divided into 3 dimensions nine unique items for each subscale as follow: Trust in the Supervisors (9 items); trust in co-workers, (9 items); and trust in the organization management (9 items). Each item was measured by five Likert scale ranged as: (strongly agree $=5$, agree $=4$, neutral $=3$, disagree $=2$, and strongly disagree $=1$ ). The tools' reliability was checked and statistically measured. Cronbach's Alpha test was used to determine the tools' internal accuracy. Cronbach's alpha had a value of (0.88). The scoring system was ranged from 27 to 135, and it divided into three levels as follow:

- Low organizational trust ranged from 27 to 63.

- Moderate organizational trust ranged from 64 to 99.

- High organizational trust ranged from 100 to 135.

Tool IV: Turnover Intention Scale.

This tool developed by Bothma \& Roodt, (2013) in English language to assess Turnover Intention. It consists of 6 items each item was measured by five Likert scale ranged as: (strongly agree $=5$, agree $=4$, neutral $=3$, disagree $=2$, and strongly disagree $=1$ ) with Cronbach's alpha values estimating internal consistency reliability was (0.91). The scoring system was ranged from 6 to 30, and it divided into three levels as follow:

- Low turnover intention ranged from 6 to 14.

- Moderate turnover Intention ranged from 15 to 22.

- High turnover Intention ranged from 23 to 30.

\section{Pilot Study:}

It was performed on $10 \%$ of the sample (30 nurses) after the study resources were developed but before the actual data collection. The aim of the pilot study was to see if the study tools were feasible and applicable. The pilot research was also used to assess the amount of time needed to fill the instruments. During data collection, no changed occurred in the tools from the expertise so, pilot study data were included in the main study sample.

\section{Ethical Considerations}

The research ethics committee of Minia University's Faculty of Nursing released an official letter. The dean of Minia University's Faculty of Nursing gave his permission to conduct the research. Directors of hospitals and nursing directors gave their permission and consent. The heads of the departments gave their permission and approval. After describing the essence and intent of the study, the participants gave their verbal consent. At any time, a research participant has the right to refuse to participate or withdraw from the study for any reason. During data collection, the privacy of study participants was taken into account. Plagiarism was avoided, and intellectual property rights were maintained, and participants were told that all of their data was highly confidential. Anonymity was also assured by assigning a number to each nurse instead of their names to protect their privacy.

\section{Procedures:}

- The tools have been translated into Arabic. Translation and back translation were conducted to confirm accuracy and appropriateness.

- The researchers clarified the study's intent, existence, and significance to each participant in order to obtain better cooperation during the research's implementation.

- The researchers gave the study tools to nurses one by one in their hospitals.

- The questionnaire was expected to take between 25 and 30 minutes to complete.

- The researchers double-checked each method to ensure that the nurse had accomplished all of the tasks.

- Data was collected between September and October 2020, during the morning and afternoon 
shifts, according to the nurses' and researchers' schedules.

\section{Statistical Analysis:}

SPSS version 25.0 was used for data entry and statistical analysis. For qualitative variables, descriptive statistics such as frequencies and percentages, mean and standard deviation, and spearman's rank correlation coefficient were used; for quantitative variables, mean and standard deviation, and spearman's rank correlation coefficient were used. At a p-value of 0.05 , the results were considered statistically important.

\section{Results}

Table (1): Distribution of staff nurses according to their Demographic characteristics data among staff nurses.

\begin{tabular}{|c|c|c|}
\hline \multirow[t]{2}{*}{ Demographic characteristics data } & \multicolumn{2}{|c|}{$\begin{array}{c}\text { Staff Nurses } \\
(\mathbf{3 0 1})\end{array}$} \\
\hline & No & $\%$ \\
\hline \multicolumn{3}{|l|}{ 1. Age } \\
\hline - $>30$ & 150 & 49.8 \\
\hline - $\quad 30-<40$ & 80 & 26.6 \\
\hline - $\quad<40$ & 71 & 23.6 \\
\hline Mean \pm SD & \multicolumn{2}{|c|}{$31.6412 \pm 9.07657$} \\
\hline \multicolumn{3}{|l|}{ 2. Sex } \\
\hline - $\quad$ Male & 97 & 32.2 \\
\hline - Female & 204 & 67.8 \\
\hline \multicolumn{3}{|l|}{ 3. Marital status } \\
\hline - $\quad$ Single & 92 & 30.5 \\
\hline - $\quad$ Married & 205 & 68.1 \\
\hline - Divorce & 2 & 0.7 \\
\hline - Widowed & 2 & 0.7 \\
\hline \multicolumn{3}{|l|}{ 4.Qualifications } \\
\hline - $\quad$ Diploma & 141 & 46.8 \\
\hline - Institute & 137 & 45.5 \\
\hline - Baccalaureate & 21 & 7.0 \\
\hline - $\quad$ Masters and PhD & 2 & 0.7 \\
\hline \multicolumn{3}{|l|}{ 5. Years of experience } \\
\hline$\cdot \quad>5$ & 33 & 11 \\
\hline - $5-<15$ & 159 & 52.8 \\
\hline - $\quad<15$ & 109 & 36.2 \\
\hline Mean \pm SD & \multicolumn{2}{|c|}{$11.1262 \pm 8.40540$} \\
\hline \multicolumn{3}{|l|}{ 6. Residence } \\
\hline - Urban & 98 & 32.6 \\
\hline - $\quad$ Rural & 203 & 67.4 \\
\hline
\end{tabular}

Table (2): Distribution of total work place bullying and its dimensions among staff nurses.

\begin{tabular}{|c|c|c|}
\hline Dimensions & No & $\%$ \\
\hline \multicolumn{3}{|l|}{ Work related bullying } \\
\hline - $\quad$ Low level & 18 & 6.0 \\
\hline - $\quad$ Moderate level & 55 & 18.3 \\
\hline - $\quad$ High level & 228 & 75.7 \\
\hline \multicolumn{3}{|l|}{ Personal related bullying } \\
\hline - $\quad$ Low level & 25 & 8.3 \\
\hline - $\quad$ Moderate level & 99 & 32.9 \\
\hline - $\quad$ High level & 177 & 58.8 \\
\hline \multicolumn{3}{|l|}{ Physically intimidating bullying } \\
\hline - $\quad$ Low level & 40 & 13.3 \\
\hline - $\quad$ Moderate level & 140 & 46.5 \\
\hline
\end{tabular}




\begin{tabular}{|l|c|c|}
\hline \multicolumn{1}{|c|}{ Dimensions } & No & \% \\
\hline$\bullet \quad$ High level & 121 & 40.2 \\
\hline Total work place bullying & & \\
\hline$\bullet \quad$ Low level & 47 & 15.7 \\
\hline$\bullet \quad$ Moderate level & 57 & 18.9 \\
\hline$\bullet \quad$ High level & 197 & 65.4 \\
\hline
\end{tabular}

Table (3): Distribution of total organizational trust and its dimensions among staff nurses.

\begin{tabular}{|c|c|c|}
\hline Dimensions & No & $\%$ \\
\hline \multicolumn{3}{|l|}{ Trust in supervision } \\
\hline - $\quad$ Low level & 145 & 48.2 \\
\hline - $\quad$ Moderate level & 97 & 32.2 \\
\hline - $\quad$ High level & 59 & 19.6 \\
\hline \multicolumn{3}{|l|}{ Trust in coworker } \\
\hline - $\quad$ Low level & 40 & 13.3 \\
\hline - $\quad$ Moderate level & 140 & 46.5 \\
\hline - $\quad$ High level & 121 & 40.2 \\
\hline \multicolumn{3}{|l|}{ Trust in management } \\
\hline - $\quad$ Low level & 185 & 61.5 \\
\hline - $\quad$ Moderate level & 57 & 18.9 \\
\hline - $\quad$ High level & 59 & 19.6 \\
\hline \multicolumn{3}{|l|}{ Total organizational trust } \\
\hline - $\quad$ Low level & 189 & 62.8 \\
\hline - $\quad$ Moderate level & 61 & 20.3 \\
\hline - $\quad$ High level & 51 & 16.9 \\
\hline
\end{tabular}

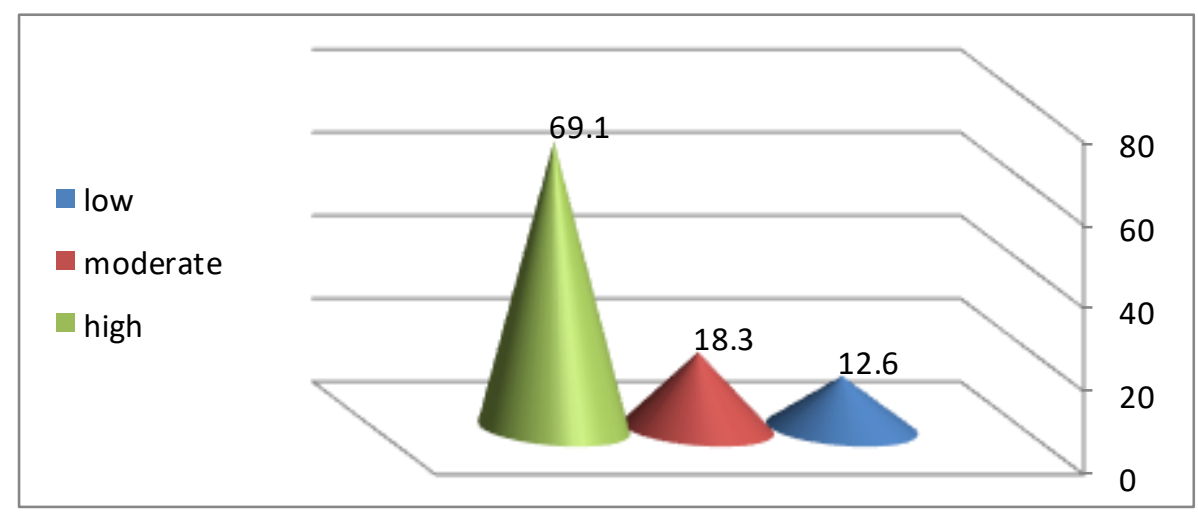

Figure (1): Distribution of total turnover intension among staff nurses (No=301).

Table (4): Correlation between work place bullying, organizational trust and turnover intension questionnaire among staff nurses.

\begin{tabular}{|l|c|c|c|c|c|c|}
\hline \multirow{2}{*}{ Variables } & \multicolumn{2}{|c|}{ Work place Bullying } & \multicolumn{2}{c|}{ Organizational trust } & \multicolumn{2}{c|}{ Turnover intension } \\
\cline { 2 - 7 } & $\mathbf{r}$ & $\mathbf{P}$ & $\mathbf{r}$ & $\mathbf{p}$ & \multicolumn{1}{c|}{$\mathbf{~}$} & $\mathbf{p}$ \\
\hline Work place bullying & & & -.209 & $\mathbf{. 0 0 0} * *$ & $\mathbf{. 8 5 5}$ & $\mathbf{. 0 0 0} * *$ \\
\hline Organizational trust & $\mathbf{- . 2 0 9}$ & $\mathbf{. 0 0 0} * *$ & & & $\mathbf{- . 2 5 8}$ & $.000 * *$ \\
\hline Turnover intension & .855 & $.000 * *$ & -.258 & $.000 * *$ & & \\
\hline
\end{tabular}

$$
p \leq 0.05 \text { (significant) * statistically significant difference }
$$


Table (5): Relation between studied variables and socio demographic data among nursing staff

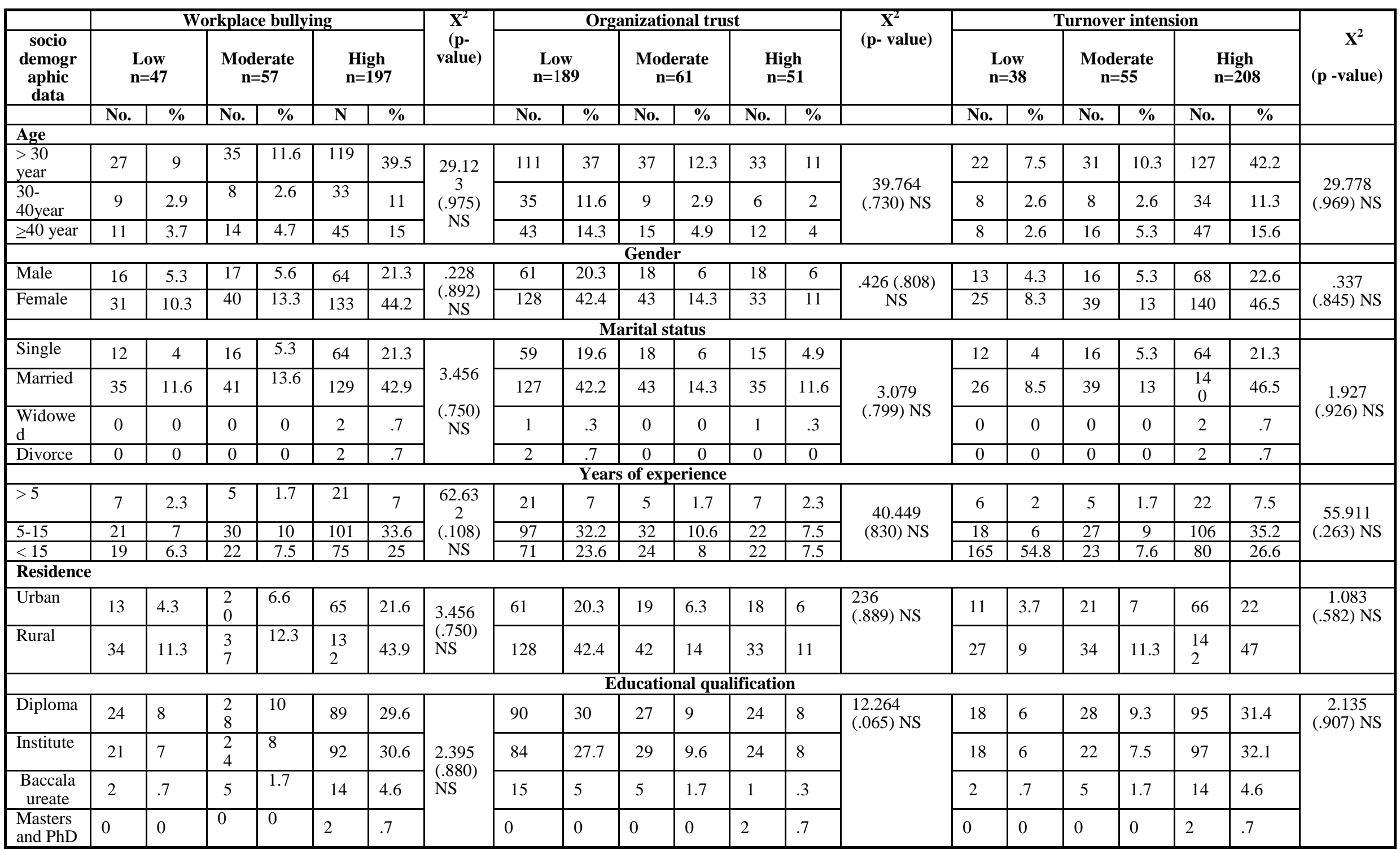
$p \leq 0.05$ (significant) * statistically significant difference

NS: Non significant 
Table (1): Shows that, about half (49.8\%) of staff nurses are in the age less than 30 years and more than two thirds of them are females, married and resided rural areas respectively $(67.8 \%, 68.1 \% \& 67.4 \%)$. In addition to, around half of the studied sample qualified as diploma nursing degree and have 5-15 years of experience respectively (46.8\% \& 52.8\%).

Table (2): Explains that, about two third of studied nurses $(65.4 \%)$ have high total work place bullying level. While, $(18.9 \%)$ of them have moderate total work place bullying level, and only $(15.7 \%)$ of them have low total work place bullying level.

Table (3): Summarizes that, less than two third of studied nurses $62.8 \%$ have low total organizational trust level. While, $20.3 \%$ of them have moderate total organizational trust level and only, $16.9 \%$ of them have high total organizational trust level.

Figure (1): Indicates that, more than two third of studied nurses $69.1 \%$ have high total turnover intension level. While, $18.3 \%$ of them have moderate total turnover intension level and only $12.6 \%$ of them have low turnover intension level

Table (4): Summarizes that, there are statistically significant positive correlation between work place bullying and turnover intension among staff nurses $\mathrm{r}=$ $(.855) \mathrm{P}$-value $=\left(.000^{* *}\right)$. While , there are statistically significant negative correlation between work place bullying and organizational trust for staff nurses $r=(-$ .209) $\mathrm{P}$-value $=(.000 * *)$, and there are statistically significant negative correlation between turnover intension and organizational trust for staff nurses $\mathrm{r}=(-$ .258) $\mathrm{P}$-value $=(.000 * *)$.

Table (5): Illustrates that; there is no statistical significant differences between workplace bullying, organizational trust, turnover intension and socio demographic data for study subjects

\section{Discussion}

Bullying in the workplace is a global phenomenon that, if not tackled properly, can have a huge effect on the quality of care given to patients as well as nurses' decisions to stay in or leave their hospitals. As a result, successful retention techniques necessitate a thorough understanding of the factors at work in order to retain highly motivated nurses committed to organizational performance. So, the current study aimed to assess workplace bullying and its effect on organizational trust and turnover intention among nursing staff.

In this study, about half of staff nurses are in the age less than 30 years and more than two thirds of them are females, married and resided rural areas. In addition to, around half of the studied sample qualified as diploma nursing degree and have $5-<15$ years of experience. This finding may be explained by the fact that female nurses made up the majority of nurses who graduated from high schools of nursing, professional institutions of nursing, and nursing faculties. Also, the fact that women continue to make up the bulk of nurses.

This result matched with the demographic characteristics of a study done in Egypt in private and public hospitals by Elewa \& El Banan, (2019) who recorded that females made up $72 \%$ of their study group, more than half of whom were married, and more than half of the sample had a diploma degree. Also, El-Houfy et al., (2015), reported that, males made up more than half of the medical teams, while females made up the bulk of the nursing teams $(82.1 \%)$. In addition to, these findings are greatly consistent with Duman, (2012) who noted that nursing is still largely a female-dominated occupation around the world.

Regarding workplace Bullying this study showed that about two thirds of the studied sample reported that they highly exposed to workplace bullying and about three quarter of them reported that work related bullying are the most common type of workplace bullying that they exposed to which should be a cause for concern as it brings special attention to bullying in the health care and high incidence of bullying. This may be explained by researchers by two rationales first one may be due to nursing in general had negative professional image.

As well, the second rational for this result might be due to the young age of the participants, poor hospital conditions, such, role conflict, work-overload, staff shortages, especially the fact that our study was conducted at the time of the Covid 19 Pandemic, long working hours, gaps or unclear in communication networks, there is no clear standard for the measurement of bullying behaviors and there are no standardized terms of bullying in the form of a definition or list of behaviors may be problematic which make the employees like nurses may not perceive bullying as researchers do similarly there are no clear guidelines for combating it.

This result congruent with several studies done both in Egypt or outside our country in different period of times; as Mohamed et al., (2020) who reported that more than half of their studied sample experience bullying at workplace, Trepanier et al., (2016), \& Al-Wehedy et al., (2012) also support this study as they reported that most nursing staff were exposed to workplace bullying. Moreover, Abbas et al., (2010) revealed that more than half of nurses were exposed to violent behavior during work. In addition, Kwok et al., (2006) reported that bullying had been experienced by more than three quarters of nurses who included in their studied sample.

On contrary this result is disagreed with Karatza (2016) who found that the majority of respondents 
had not witnessed any bullying incidents at work in the previous year. Also, Budin et al., (2013), found that most nurses claimed they were not subject to bullying. This difference between studies may be due to a number of factors such as history, working atmosphere, availability, and nursing staff weaknesses, as well as nurses' knowledge of how to respond to and cope with bullying at work.

Regarding organizational trust, this study showed that less than two third of the studied sample have low total organizational trust score additionally, there are statistically significant negative correlation and between workplace bullying and organizational trust for staff nurses. This may be due to the high incidence of workplace bullying within the organization cause psychological problems of staff nurses such as distress, anger, increase turnover rate and lower job satisfaction all psychological problems especially with poor and unclear communication networks to report regarding these negative acts which affected negatively on nurses' organizational trust. This supported by the point of view of (Vokić et al, .2020) who clarifies effective communication plays a critical role in the creation of organizational trust and relationships among employees.

Similarly there is statistically significant negative correlation between turnover intension and organizational trust for staff nurses which supported with a comparative study done in Egypt between private and public hospitals, carried out by Elewa \& El Banan, (2019) who indicated that there was a statistically significant negative association between organizational trust and bullying and Abdel Wahid,( 2020 ) who stated that workplace trust and authentic leadership were negatively and substantially associated with work-related bullying.

Moreover, current study showed that more than two thirds of the studied sample had a highly turn over intention also there were positive correlation statistically significant between workplace bullying and turnover intension which may be explained that nurses who wanted a turnover intention as a way of unhealthy coping strategies to avoid such negative acts at work as this consider an escape behavior to remove the source of the problem which affect negatively on all health care system which already suffer from limited resources.

These findings supported by previous studies Bahjat et al., (2017); Coetzee \& Oosthuizen, (2017); Coetzee \& van, (2017); Mathisen et al., (2008); Quine, (1999); \& Rasool et al., (2013). As they reported that turnover intention considers a negative outcome for exposure to workplace bullying. Also, Rosario-Hernández \& Millán, (2018) explained that workplace negative actions can deteriorate nurses' psychological and physical conditions, depleting their resources to handle such stressors, and as a result, exposed workers view leaving their organizations as the only way to avoid workplace bullying behaviors from being exposed and to protect their resources. Finally, this study declared that there are no significant differences among the study variables and sociodemographic data which match with Alcantara et al., (2017) noticed that there is no significant correlation between personal data and workplace bullying. Opposite to study done by Ariza et al, (2013) who stated that the demographic data of the subjects are linked to workplace bullying. Also this study explained that there are no significant differences among the organizational trust and sociodemographic data, On contrary this result is disagreed with Al- Hamed, (2018) who explained that marital status, credentials, years of experience, and organizational trust all varied significantly. and that there are no substantial differences between turnover intention and sociodemographic data, according to this report. This result is disagreed with Aryo \& Viera, (2018) who clarified that there was a substantial difference in turnover intention amongst sociodemographic nurses.

\section{Conclusion}

The findings of the current study affirmed that about two third of staff nurses had the highest percentage regarding workplace bullying, and less than two third of them had the lowest rate regarding the understanding of organizational trust and more than two third of studied nurses have high total turnover intension level. Also, there were strong a positive correlation between work place bullying and turnover intension for staff nurses. While, there were a negative correlation between work place bullying and organizational trust for staff nurses, and there were a negative correlation between turnover intension and organizational trust for staff nurses.

\section{Recommendations:}

- Minimize workplace bullying and the risk of attrition, the organization should encourage and establish a positive and trusting atmosphere among nurses' workers.

- Increase organizational trust and minimize nursing staff turnover, health care organizations should empower managers to use good communication skills and inspire clear expectations and procedures to recognize and combat workplace bullying.

- Develop working environments by hospital managers that minimize the risk of nurse turnover and use organizational confidence behaviors that enable nurses to work in humanitarian conditions. 
- Develop polices by administrators to prevent workplace bullying that occur from patients, their relatives' and others.

- Develop a strategic plan in healthcare environments to increase organizational confidence and minimize staff nurse turnover.

- Develop and enforce strategies to minimize the frequency of workplace bullying for healthcare institutions.

\section{References}

- Abbas M, Fiala L, Abdel Rahman A, \& Fahim E., (2010): Epidemiology of workplace violence against nursing staffing Ismailia Governorate, Egypt. J Egypt Public Health Assoc., 85 (1-2), 2943.

- Abdel Wahid A., (2020): Workplace Trust and Authentic Leadership as Predictors of Workrelated Bullying among Staff Nurses.

- Al- Hamed, G., (2018): The difference of organizational trust between public and private hospital in Jordan. IJRDOJournal of Social Science and Humanities Research ISSN : 24562971.3(3), 48-56

- Al Omar, M., Salam, M., \& Al-Surimi, K. (2019): Workplace bullying and its impact on the quality of healthcare and patient safety. Human resources for health, 17(1), 1-8.6.

- Alcantara, G., Claudio, E., \& Gabriel, A. (2017): Prognosis of Workplace Bullying in Selected Health Care Organizations in the Philippines, 154-174. http://doi.org/10.4236/jss.2017.59012.

- Alliance, W. (206): 1st National Education Survey about workplace bullying in Puerto Rico. In Conference presented at the "2nd Educational Discussion on Workplace Bullying", Turabo University, Gurabo, Puerto Rico.

- Al-Wehedy A, El-Sayed R. \& Abd Elmouty S. (2012): violence against nurses working at an Emergency Hospital, Egypt. Poster. In 3rd international conference on violence in health sector.

- Ariza-Montes, A., Muniz, N., Montero-Simo, M., \& Araque- Padil, R. (2013): Workplace Bullying among Healthcare Workers. International Journal of Environmental Research and Public Health, 10(8).

- Aryo Dewanto \& Viera Wardhani (2018): Nurse turnover and perceived causes and consequences: a preliminary study at private hospitals in Indonesia Proceedings of the 3rd International Conference on Nursing (ICON) 2017

- Ayangeawam, J., Tertindi, M., \& Tyokyaa, L. (2014): Resilience and Organizational Trust as
Correlates of Work Engagement among Health Workers in Makurdi Metropolis. European Journal of Business and Management Online), 6(39), 2222-2839.

- Bahjat, E., Aljawazneh, B., Moh, Z., Smadi, A., \& Ziad, S. (2017): Workplace bullying as a predictor of intention to leave among workers at the industrial organizations in Jordan. International Journal of Academic Research in Economics and Management Sciences, 6(1), 1539. doi: 10.6007/ IJAREMS/v6-i1/2559.

- Bahjat, E., Aljawazneh, B., Moh, Z., Smadi, A., \& Ziad, S. (2017): Workplace bullying as a predictor of intention to leave among workers at the industrial organizations in Jordan. International Journal of Academic Research in Economics and Management Sciences, 6(1), 1539.

- Basit, G., \& Duygulu, S. (2018): Nursese organizational trust and intention to continue working at hospitals in Turkey. Collegian, 25(2), 163-169.

http://doi.org/10.1016/j.colegn.2017.05.003.

- Bothma, C., \& Roodt, G. (2013): The validation of the Turnover Intention Scale. SA Journal of Human Resource Management, 11, 1-12. https://doi.org/10.4102/sajhrm.v11.i1.507

- Budin W., Brewer C., Chao Y-Y. \&, Kovner C., (2013): Verbal abuse from nurse colleagues and work environment of early career Registered Nurses. Journal of Nursing Scholarship; 45(3), 308- 316.

- Chen, S., Wu, W., Chang, C., Lin, C., Kung, J., Weng, H. \& Lee, S. (2015): Organizational justice, trust, and identification and their effects on organizational commitment in hospital nursing staff. BMC health services research, 15(1), 363.

- Coetzee, M. \& Oosthuizen, R.M. (2017): Work role psychosocial flourishing: Its mediation role on workplace bullying and employee turnover intention. Journal of Psychology in Africa. 27(3), 211-215.

- Coetzee, M. \& van D, (2017): Workplace bullying and turnover intention: Exploring work engagement as a potential mediator. Psychological Reports, 121(2), 375-392. doi: 10.1177/0033294117725073.

- Dirks, K., \& Ferrin, D. (2002): Trust in leadership: Meta-analytic findings and implications for research and practice. Journal of applied psychology, 87(4), 611.

- Duman, N.B. (2012): Reflections of Female Domination in the Profession over the Nursing Strength: Turkey Sample, International Journal of Business and Social Science, International Journal 
of Business and Social Science,3 (24):182187.

- Einarsen, S., Hoel, H., \& Notelaers, G. (2009): Measuring exposure to bullying and harassment at work: Validity, factor structure and psychometric properties of the Negative Acts QuestionnaireRevised. Work \& Stress, 23(1), 24-44. doi:10.1080/ 02678370902815673.

- El-Houfey A., Nahed SH. Abo El-Maged, Yasser M. Elserogy \& Walid El Ansari (2015): Workplace Bullying Against Medical and Nursing Team Working at Emergency Departments in Assiut University Hospital. IOSR Journal of Nursing and Health Science. Volume 4, Issue 2. PP 01-09 www.iosrjournals.org.

- Elewa, A., \& El Banan, S. (2019): Organizational culture, organizational trust and workplace bullying among staff nurses at public and private hospitals. International Journal of Nursing Didactics, 9(4), 10-20.

- Fard, P., \& Karimi, F. (2015): The Relationship between Organizational Trust and Organizational Silence with Job Satisfaction and Organizational Commitment of the Employees of University. International Education Studies, 8(11), 219-227.

- Gebregziabher Dawit, Eskedar Berhanie, Hagos Berihu, Addis Belstie and Girmay Teklay (2020): The relationship between job satisfaction and turnover intention among nurses in Axum comprehensive and specialized hospital Tigray, Ethiopia. BMC Nursing available @ https//doi.org/10.1186/12912-020-00468-0

- Hayes LJ, O’Brien-Pallas L, Duffield C, et al. (2012): Nurse turnover: a literature review-an update. Int J Nurs Stud.; 49(7):887-905.

- Karatza C, Zyga S, Tzlaferi S, \& prezerakos p., (2016): Workplace Bullying and General Health Status among the Nursing Staff of Greek Public Hospitals. Annals of General Psychiatry.

- Kwok R, Law Y, Cheung M, Fung V, \& et al., (2006): Prevalence of workplace violence against nurses in Hong Kong. Hong Kong Med.; 12 (1): 6-9.

- Mathisen, G., Einarsen, S., \& Mykletun, R. (2008): The occurrences and correlates of bullying and harassment in the restaurant sector. Scandinavian Journal of Psychology, 49(1), 5968.

- Mohammed A, Abo Gad R, \&Shokir M, (2020): Workplace Bullying and its effect on Staff Nurses' Work Engagement. Tanta Scientific Nursing Journal Vol. 18 No. 1 Available @ https://tsnj.journals.ekb.eg/article_107693.html.

- Nagib A., \& Mohamed, E. (2020): The Relation between Bullying Workplace, Organizational Support, and Work Engagement as Perceived by
Staff Nurses. Indian Journal of Public Health Research \& Development, 11(1).

- Quine, L. (1999): Workplace bullying in NHS community trust: survey. British Medical Journal, 318, 228232. doi: 10.1136/bmj.318.7178.228.

- Rasool, F., Aruz, F., Hassan, A., Rafi, A., Kashif, A.R. (2013): Workplace bullying and intention to leave: The moderating effect of the organizational commitment. Information Management and Business Review, 5(4), 175-180.

- Rosario-Hernández, E., \& Millán, L. (2018): Effect of the exposure to workplace bullying on turnover intention and the mediating role of job satisfaction, work engagement, and burnout. Revista Interamericana de Psicología Ocupacional, 37(1), 26-51.

- Takase M. (2010): Concept analysis of turnover intention: implications for nursing management. Collegian; 17: 3-12.

- Top, M., Akdere, M., \& Tarcan, M. (2015): Examining transformational leadership, job satisfaction, organizational commitment and organizational trust in Turkish hospitals: public servants versus private sector employees. The International Journal of Human Resource Management, 26(9), 1259-1282.

- Trêpanier S, Fernet C, Austin S, \& Boudrias V, (2016): Work environment antecedents of bullying: A review and integrative model applied to registered nurses. International Journal of Nursing Studies; 55: 85-97.

- Vokić, N., Bilušić, M., \& Najjar, D. (2020): Building organizational trust through internal communication. Corporate Communications: An International Journal.

- Yamada D, Duffy M, \& Berry P. (2018): Workplace Bullying and Mobbing: Definitions, Terms, and When They Matter. Workplace Bullying and Mobbing in the United States. ; 2(1): 2-6.

- Yamane, T. (1967): Statistics: An introductory analysis (No. HA29 Y2 1967).

- Yang, F., Tsai, Y., \& Tsai, K. (2014): The influences of ethical climate on Journal of Organizational Innovation, 6(4), 72-90. Retrieved from http://www.ijoi online.org 